\title{
Examining Surgical Patients' Expectations of Nursing Care at Kenyatta National Hospital in Nairobi, Kenya
}

\author{
Elwin Shawa (MSc N) \\ Mzuzu University, Malawi \\ Lilian Omondi (PhD, MSc N) \\ University of Nairobi, Kenya \\ Balwani Chingatichifwe Mbakaya (MPH)
}

St John's College of Nursing \& Midwifery, Malawi

doi: 10.19044/esj.2017.v13n24p344 URL:http://dx.doi.org/10.19044/esj.2017.v13n24p344

\begin{abstract}
Good service is defined when it meets the expectations of its customers. Likewise, nursing is a profession that aims at meeting patients' needs and expectations. Many studies have been done at Kenyatta National Hospital (KNH) in Nairobi, Kenya regarding customer care satisfaction in various departments. However, little is known on patients' expectations regarding nursing care. Therefore, this study was carried out to examine surgical patients' expectations of nursing care in surgical wards. A descriptive cross-sectional quantitative study was conducted at Kenyatta National Hospital in general surgical wards from April to June, 2012. The study population were adult postoperative patients admitted in the general surgical wards. The sample size was 168 and systemic random sampling technique was used in selecting the participants. The data collection tool was a structured questionnaire with open and closed questions. Ethical clearance was obtained from University of Nairobi and Kenyatta National Hospital Ethics Committee. Participation in the study was voluntary and based on patients' ability to give informed consent. A total of 167 adult patients from general surgical wards responded to the questionnaire. Most patients agreed that they expected nurses to be knowledgeable with an average response of $86 \%$ and strongly disagreed that nurses should be rude and harsh (44\%). $46 \%$ of participants agreed that they expected nurses to be responsive with mean of $(\mathrm{M}=3.61)$. It was found that most patients' expectations were met and because of this, many felt satisfied with the nursing care provided. It is recommended that nurses should pay more attention to what patients expect from nursing care.
\end{abstract}

Keywords: Patient's expectations; Nursing care; Patient's satisfaction 


\section{Introduction}

According to World Health Organization (WHO, 2000), quality has been defined as the process of meeting the needs and expectations of patients and health service staff. Buttell, Hendlier, \& Daley, (2007) also defined quality as a degree to which health services for individual and populations increase the likelihood of desired health outcomes, are consistent with current professional knowledge and meet the expectations of health users. An important measure of quality health care is the extent to which patients' expectations are met (HRSA, 2011). It has been observed from the above definitions that patients' expectations make one of the defining characteristics for the service to be regarded of quality. Therefore, good service is defined when it meets the expectations of its customers. Likewise, nursing is a profession that aims at meeting patients' expectations. Patients undergoing surgical procedures expect a lot from nurses because they represent the image of health care institutions. As portrayed by Zhao \& Akkadechanunt, (2011), patients see nurses' interaction with others on the care team and can draw conclusions about the hospital based on their observations. Patients expect nurses to be polite, kind and knowledgeable, (Nankhumbi, 2005). A study conducted in Turkey on the patients' expectations and satisfaction of nursing care, also revealed that patients' expectations of nursing care were found to be cheerfulness, concern, understanding, courtesy and benevolence (Ozsoy, et.al, 2007). This is why patients' anxiety may either be alleviated or worsened depending on how the nurses address patients' expectations. According to Redsell, Jackson, Hastings A, Stokes, and Bakers (2007), patients may not expect their general practitioner to have the time to listen to their concerns, but they might expect a nurse to do so. This means that patients are expecting nurses to give full attention to their concerns. As reported by Farooq \& Rasool, (2012) in a study conducted in Pakistan, $84 \%$ of patients had negative experiences as they observed that nurses were not attentive to their needs. Similar findings were also found in a study done by Shirley \& Norazliah, (2012), which indicates that Surgical patients were highly satisfied with nurses' attentiveness and openness of informality. It was also found that most of the patients rated "highly satisfied" with "nurses' manner in going about their work

It is believed that patients' expectations determine patients' satisfaction with the nursing care provided. Reck, (2013) found out that the higher a patient's expectations for their care, the higher would be their satisfaction. And conversely, the lower a patient's expectations, the lower their eventual satisfaction. This means that the more patients' expectations are met by nurses, the more satisfied the patients would be. Since most patients would like to visit hospitals that are considered to be providing 
quality nursing care. It is expected that quality nursing care satisfies the needs of patients. As health professionals, nurses are accountable for quality and systematic improvement of nursing practice (Burhans, \& Alligood, 2010). Therefore, meeting patients' expectations is one of professional responsibility and accountability for quality improvement. It was also observed that quality of care demands that much attention should be paid to the needs of patients and clients (Ghana Health services, 2004). It was further noted that health care workers are expected to practice according to set standards through the use of methods that have been tested to be safe, affordable and reduce deaths, illness and disability.

Kenyatta National Hospital (KNH) has conducted numerous customer care satisfaction surveys, but little is known on patients' expectations regarding nursing care. It was against this background that this study focused on examining patients' expectations of nursing care in general adult surgical wards at Kenyatta National Hospital.

\section{Methodology}

This was a quantitative cross-sectional study conducted at Kenyatta National Hospital, Nairobi in Kenya. One hundred and sixty-eight subjects were interviewed. Subjects were recruited using systemic random sampling technique. The first two patients in the register books were selected by random to determine the starting point. Sampling interval for systematic sampling was determined by dividing sample size by total population of patients in the register.. The criteria for inclusion were adult surgical patients aged 18 years or older, who had spent two or more days postoperatively in the ward, were in stable general condition, fully conscious, agreed to participate in this research, and signed informed consent. The data collection tool was adapted from Hospital Consumers Assessment of Healthcare Providers and Systems (HCAPS) survey tool developed by Centers for Medicare and Medicaid Services in UK. It was endorsed by the National Quality Forum, a national organization that represents the consensus of many healthcare providers, consumer groups, professional associations in UK. It was then modified to meet the study objectives. It was also reviewed and approved by the KNH/UON Research Ethics committee. The data was collected from April 2012 to June 2012. Structured questionnaire with closed and open ended questions written in both English and Kiswahili were used. The questionnaire had sections seeking information on participants' demographic data; patients' expectations, experiences and challenges with nursing care. It took an average of twenty minutes per participant in completing the questionnaire. Participants were assisted in filling in the questionnaire by investigators. Participants were also asked to explain how they perceived the nursing care and the level of satisfaction. The data were 
processed using SPSS for Window version 20.0 with subsequent descriptive statistical analysis.

\section{Results}

\section{Social demographic data}

A total of 168 adult surgical patients were approached and 167 $(99.4 \%)$ returned the questionnaires fully completed. Most of the respondents were males $(54.2 \%)$ and age of the respondents ranged from less than 19 years to 60 years and above. The age group with more response was 30 - 39 years, who were $54(32.1 \%)$ with mean of 3.02 and SD of 1.628, followed by age group of $20-29$ years, who were 50 (29.8\%). Among the respondents, $71(42.3 \%)$ were married, $44(26.2 \%)$ never married, 22 $(13.1 \%)$ were widowed, while $7(4.2 \%)$ were separated. Furthermore, $68(40.5 \%)$ had attained college/tertiary level of education, 54 (32.1) had secondary education, $29(17.3 \%)$ had primary, and $16(9.5 \%)$ had not attended any formal education. Christians were $138(82.1 \%)$, and 29(17.3\%) were Muslims. In terms of occupation, 65 (38.7\%) were business persons, 41 (24.4\%) were professionals, and 31(18.5\%) were casual labourers. Finally, the social demographic data revealed that $80(47.6 \%)$ were urban residents and $52(31.0 \%)$ were from rural areas.

\section{Patients' expectations from nurses}

Table 1: Patients' Mean Responses on patients Expectations by Age distribution in Surgical Wards at KNH, April-June, 2012

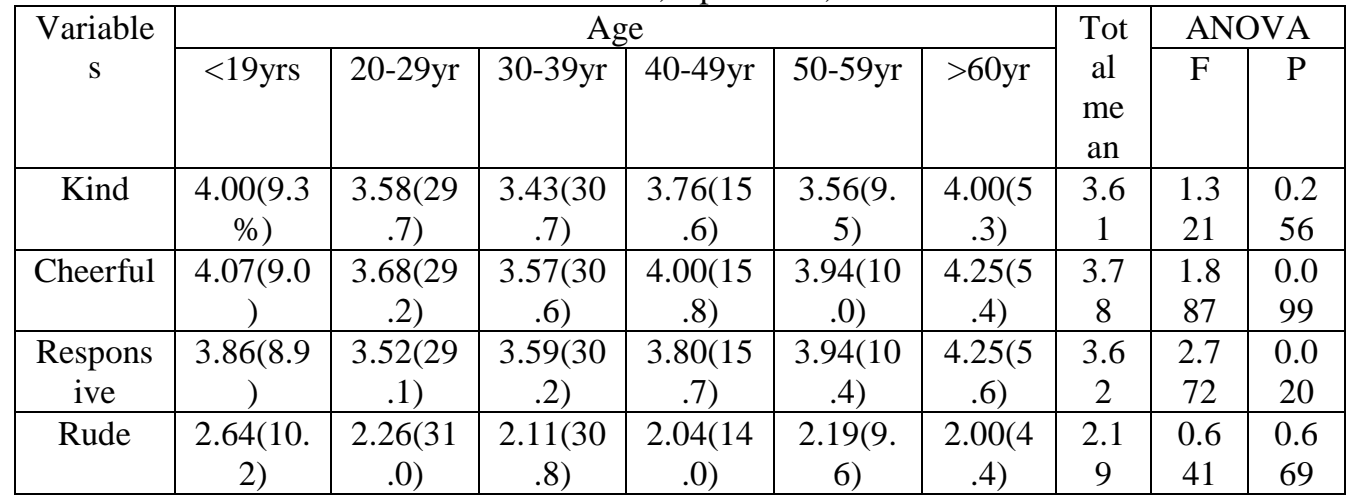

Note. Numbers in parentheses ( ) denote Percentage \%. Significant at $\mathrm{p}<0.05$

Table 1 shows mean responses by age groups. Patients were expecting nurses to be kind $(\mathrm{m}=3.61)$, cheerful $(\mathrm{m}=3.78)$ and responsive $(\mathrm{m}=3.62)$. 
Table 2: Participants' mean responses by gender and religion on patients' expectations in Surgical Wards at KNH, April-June, 2012

\begin{tabular}{|c|c|c|c|c|c|}
\hline \multirow{2}{*}{ Variables } & \multicolumn{2}{|c|}{ Gender } & \multicolumn{2}{c|}{ Total mean } & \multicolumn{2}{c|}{ ANOVA } \\
\cline { 2 - 3 } & Male & Female & & F & P \\
\hline Kind & $3.56(53.7)$ & $3.61(46.3)$ & 3.61 & 0.568 & 0.452 \\
\hline Cheerful & $3.76(54.2)$ & $3.80(45.8)$ & 3.78 & 0.101 & 0.750 \\
\hline Responsive & $3.53(53.1)$ & $3.74(46.9)$ & 3.62 & 2.467 & 0.118 \\
\hline Rude & $2.14(53.6)$ & $2.25(46.4)$ & 2.19 & 0.202 & 0.654 \\
\hline \multicolumn{7}{|c|}{ Religion } \\
\hline \multicolumn{7}{|c|}{ Christians } & 3.61 & 3.265 & 0.073 \\
\hline Kind & $3.55(81.3)$ & $3.90(18.7)$ & 3.78 & 1.540 & 0.216 \\
\hline Cheerful & $3.74(81.8)$ & $3.97(18.2)$ & 3.62 & 3.599 & 0.060 \\
\hline Responsive & $3.57(81.3)$ & $3.90(18.7)$ & 3.19 & 0.099 & 0.754 \\
\hline Rude & $2.18(82.7)$ & $2.25(17.3)$ & 2.19 & \\
\hline
\end{tabular}

Note. Numbers in parentheses ( ) denote Percentage \%. Significant at $\mathrm{p}<0.05$

The table 2 above shows the mean participants responses by gender and religion on what they were expecting from nurses. The study revealed that females had a higher mean response (mean=3.61-3.80) than males' mean response (mean $=3.56-3.76)$ in agreeing that they expected nurses to be kind, cheerful, responsive and not to be rude. Participants' responses by religion, revealed most participants were in agreement with that nurses should be kind, cheerful and responsive(mean> 3.61) and did not agree that nurses should be rude $(\mathrm{m}=2.19)$.

Table 3: Patients' mean responses on patients' expectations by marital status in Surgical Wards at KNH, April-June, 2012

\begin{tabular}{|c|c|c|c|c|c|c|c|c|}
\hline \multirow[t]{2}{*}{ Variables } & \multicolumn{5}{|c|}{ Marital status } & \multirow{2}{*}{$\begin{array}{c}\text { Tota } \\
1 \\
\text { mea } \\
\mathrm{n}\end{array}$} & \multicolumn{2}{|c|}{ ANOVA } \\
\hline & single & married & Divorced & $\begin{array}{c}\text { Widowe } \\
\mathrm{d}\end{array}$ & $\begin{array}{c}\text { separate } \\
\mathrm{d}\end{array}$ & & $\mathrm{F}$ & $\mathrm{P}$ \\
\hline Kind & $\begin{array}{c}3.70(27 . \\
0)\end{array}$ & $\begin{array}{c}3.52(41 . \\
4)\end{array}$ & $\begin{array}{c}3.52(13 . \\
4)\end{array}$ & $\begin{array}{c}3.82(13 . \\
9)\end{array}$ & $\begin{array}{c}3.57(4.1 \\
) \\
\end{array}$ & 3.61 & $\begin{array}{c}0.58 \\
3 \\
\end{array}$ & $\begin{array}{c}0.67 \\
5 \\
\end{array}$ \\
\hline Cheerful & $\begin{array}{c}3.86(26 . \\
9)\end{array}$ & $\begin{array}{c}3.61(40 . \\
6)\end{array}$ & $\begin{array}{c}3.78(13 . \\
8)\end{array}$ & $\begin{array}{c}4.00(13 . \\
9)\end{array}$ & $\begin{array}{c}4.29(4.8 \\
)\end{array}$ & 3.78 & $\begin{array}{c}1.69 \\
1 \\
\end{array}$ & $\begin{array}{c}0.15 \\
5\end{array}$ \\
\hline $\begin{array}{l}\text { Responsi } \\
\text { ve }\end{array}$ & $\begin{array}{c}3.68(26 . \\
8) \\
\end{array}$ & $\begin{array}{c}3.51(41 . \\
2)\end{array}$ & $\begin{array}{c}3.26(12 . \\
4)\end{array}$ & $\begin{array}{c}4.05(14 . \\
7)\end{array}$ & $\begin{array}{c}4.29(5.0 \\
)\end{array}$ & 3.62 & $\begin{array}{c}4.01 \\
8 \\
\end{array}$ & $\begin{array}{c}0.00 \\
4 \\
\end{array}$ \\
\hline Rude & $\begin{array}{c}2.36(28 . \\
6) \\
\end{array}$ & $\begin{array}{c}2.19(42 . \\
0)\end{array}$ & $\begin{array}{c}2.22(14 . \\
0)\end{array}$ & $\begin{array}{c}2.00(12 . \\
1)\end{array}$ & $\begin{array}{c}1.71(3.3 \\
)\end{array}$ & 2.19 & $\begin{array}{c}2.26 \\
6 \\
\end{array}$ & $\begin{array}{c}0.06 \\
4 \\
\end{array}$ \\
\hline
\end{tabular}

Note. Numbers in parentheses ( ) denote Percentage \%.

Table 3 above shows Participants' responses on patients' expectations by marital status were above the mean score, except that they did not agree that they were expecting nurses to be rude $(\mathrm{M}=2.19)$. 
Table 4: Participants' Responses on the Patients expectation of nursing Care in Surgical Wards at KNH, April-June, 2012

\begin{tabular}{|c|c|c|c|c|c|c|c|}
\hline Characteristics & $\mathbf{N}$ & $\begin{array}{l}\text { Strongly } \\
\text { Disagree } \\
\text { (1) }\end{array}$ & $\begin{array}{l}\text { Disagree } \\
\text { (2) }\end{array}$ & $\begin{array}{l}\text { Neutral } \\
\text { (3) }\end{array}$ & $\begin{array}{l}\text { Agree } \\
\text { (4) }\end{array}$ & $\begin{array}{l}\text { Strongly } \\
\text { agree(5) }\end{array}$ & $\begin{array}{c}\text { Average } \\
\text { Respons } \\
\text { e }\end{array}$ \\
\hline Kind & 167 & $\begin{array}{c}5 \\
(3.0 \%)\end{array}$ & $\begin{array}{c}11 \\
(6.5 \%)\end{array}$ & $\begin{array}{c}56 \\
(33.3 \%)\end{array}$ & $\begin{array}{c}67 \\
(39.9 \%)\end{array}$ & $\begin{array}{c}28 \\
(16.7 \%)\end{array}$ & 3.61 \\
\hline Cheerful & 167 & $1(0.6 \%)$ & $14(8.3 \%)$ & $41(24.4 \%)$ & $\begin{array}{c}76 \\
(45.2 \%)\end{array}$ & $\begin{array}{c}35 \\
(20.8 \%)\end{array}$ & 3.78 \\
\hline Responsive & 167 & $2(1.2 \%)$ & $14(8.3 \%)$ & $51(30.4 \%)$ & $\begin{array}{c}78 \\
(46.4 \%)\end{array}$ & $22(13.1 \%)$ & 3.62 \\
\hline Harsh & 165 & $61(36.3 \%)$ & $51(30.4 \%)$ & $24(14.3 \%)$ & $\begin{array}{c}20 \\
(11.9 \%)\end{array}$ & $9(5.4 \%)$ & 2.18 \\
\hline Honesty & 167 & $4(2.4 \%)$ & $16(9.5 \%)$ & $68(40.5 \%)$ & $\begin{array}{c}69 \\
(41.1 \%)\end{array}$ & $10(6.0 \%)$ & 3.39 \\
\hline Empathetic & 167 & $5(3.0 \%)$ & $12(7.1 \%)$ & $56(33.3 \%)$ & $\begin{array}{c}71 \\
(42.3 \%)\end{array}$ & $23(13.7 \%)$ & 3.57 \\
\hline Friendly & 167 & $5(3.0 \%)$ & $13(7.7 \%)$ & $41(24.4 \%)$ & $\begin{array}{c}74 \\
(44.0 \%)\end{array}$ & $34(20.4 \%)$ & 3.71 \\
\hline Rude & 166 & $55(32.7 \%)$ & $58(34.5 \%)$ & $26(15.5 \%)$ & $\begin{array}{c}20 \\
(11.9 \%)\end{array}$ & $7(4.2 \%)$ & 2.19 \\
\hline Polite & 167 & $7(4.2 \%)$ & $21(12.5 \%)$ & $68(40.5 \%)$ & $\begin{array}{c}57 \\
(33.9 \%)\end{array}$ & $14(8.3 \%)$ & 3.3 \\
\hline Respectful & 166 & $1(0.6 \%)$ & $8(4.8 \%)$ & $36(21.4 \%)$ & $\begin{array}{c}90 \\
(53.6 \%)\end{array}$ & $31(18.5 \%)$ & 3.86 \\
\hline $\begin{array}{l}\text { Knowledgeable } \\
\text { and competent }\end{array}$ & 167 & $1(0.6 \%)$ & $2(1.2 \%)$ & $27(16.1 \%)$ & $\begin{array}{c}51 \\
(30.4 \%)\end{array}$ & $85(50.6 \%)$ & 4.31 \\
\hline Meet my needs & 167 & $27(16.1 \%)$ & $24(14.3 \%)$ & $42(25.0 \%)$ & $\begin{array}{c}56 \\
(33.3 \%)\end{array}$ & $18(10.7 \%)$ & 3.08 \\
\hline $\begin{array}{c}\text { Communicate to } \\
\text { me }\end{array}$ & 166 & $11(6.5 \%)$ & $35(20.8 \%)$ & $47(28.0 \%)$ & $\begin{array}{c}48 \\
(28.6 \%)\end{array}$ & $25(14.9 \%)$ & 3.25 \\
\hline $\begin{array}{c}\text { Respects my } \\
\text { beliefs and values }\end{array}$ & 164 & $13(7.7 \%)$ & $25(14.9 \%)$ & $53(31.5 \%)$ & $\begin{array}{c}54 \\
(32.1 \%)\end{array}$ & $19(11.3 \%)$ & 3.25 \\
\hline $\begin{array}{l}\text { To be informed } \\
\text { and explained }\end{array}$ & 166 & $10(6.0 \%)$ & $33(19.6 \%)$ & $38(22.6 \%)$ & $\begin{array}{c}51 \\
(30.4 \%)\end{array}$ & $34(20.2 \%)$ & 3.4 \\
\hline $\begin{array}{c}\text { To be oriented to } \\
\text { the ward } \\
\text { environment. }\end{array}$ & 166 & $50(29.8 \%)$ & $18(10.7 \%)$ & $19(11.3 \%)$ & $\begin{array}{c}46 \\
(27.4 \%)\end{array}$ & $33(19.6 \%)$ & 2.96 \\
\hline
\end{tabular}

The table 4 above shows participants' responses on the expectations of nursing care. On nurses being kind, sixty seven (39.9\%) of participants agreed that they expected nurses to be kind with a mean response of $M=3.61$. Seventy six (45\%) of the participants agreed that they expected nurses to be 
cheerful with the mean response of $M=3.78$. Seventy eight $(46.4 \%)$ of the participants agreed that they expected nurses to be responsive. Sixty one $(36.3 \%)$ of participants strongly disagreed that they expected nurses to be harsh with a mean resonse of $\mathrm{M}=2.18$ and fifty five (32.7\%) strongly disagreed that they expected nurses to be rude. Fifty one (30.4\%) of participants agreed that they expected nurses to be informing them and explaining every procedure and treatment given. Eighty five $(50.6 \%)$ of the participants strongly agreed that they expected nurses to be knowledgeable and competent. On nurses being respectful, ninety $(53.6 \%)$ of the participants agreed that they expected nurses to be respectful with a mean response of $\mathrm{M}=3.86$

Figure 1: Overall responses on Patients' expectations of nursing care in Surgical wards at KNH, April-June, 2012

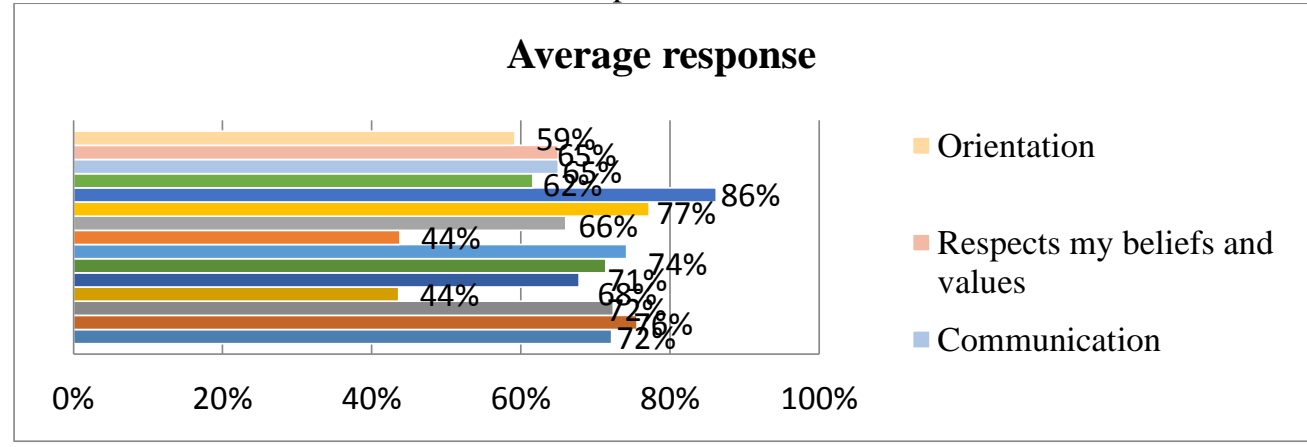

Figure 1 above shows overall responses on nurses being knowledgeable, $86 \%$ indicated that they expected nurses to be knowledgeable of their work, and $44 \%$ indicated that they did not expect nurses to be harsh and rude to patients.

\section{Discussion}

Patients' expectations are the characteristics that the patients expect from nurses as they provide nursing care to patients. If these expectations are met patients are able to appreciate the quality of nursing care they have received. The expectations under study were; that patients expected nurses to be kind, cheerful, responsive, honesty and friendly, and not to be hash and rude. Other expectations were that they expected nurses to be knowledgeable and competent, communicate to patients about the nursing care, inform and explain treatment, medication and procedures to patients and orienting patients to the ward environment and regulations.

The study revealed that almost all participants of all age groups, agreed that they were expecting nurses to be kind. But, the age groups of less than 19 years and over 60 years strongly agreed that they expected nurses to be kind. The study showed that there were no statistically significant 
differences in responses that they were expecting nurses to be kind, $p=0.256$. On nurses to be cheerful; although participants agreed that they expected nurses to be cheerful and there were no significant differences in responses that they expected nurses to be cheerful by age distribution, $\mathrm{p}=0.099$. The age group of over 60 years strongly agreed that they expected nurses to be responsive, and there were statistically significant differences in responses $(\mathrm{F}=2.272, \mathrm{p}=0.020)$. According to Aldaqal, at el, (2012), in a study conducted in Saudi Arabia, it was found that there was strong relationship between patient dissatisfaction and patient's age. It was found that factors influencing patients' satisfaction were old age and male gender. This means that when nursing care meets old aged patients' expectations, they regard the care as satisfactory. Although, all age groups strongly disagreed that they were expecting nurses to be rude, there were no significant differences in responses, $\mathrm{p}=0.669$. These findings are consistent with the study findings done in Uganda which found that patients were expecting nurses to be kind, and polite (Nankhumbi, 2005).

On participants' mean responses on the patients' expectations by gender, the study revealed that females had a higher mean response than males. This showed that more females were expecting that nurses should be kind, cheerful, and responsive and not to be rude. As reported by Aldaqal, Alghamdi, AlTurki, El-deek, and Kensarah (2012), that $88.4 \%$ of female surgical patients were satisfied with the surgical interventions provided at King Abdulaziz University Hospital in Saudi Arabia, because most of their expectations were met. Another study done in Malaysia found that most patients were happy with nurses manners $(M=3.65)$ (Shirley, and Norazliah, 2012). They were satisfied and appreciated nurses who had a calm, gentle and kind approach in their care and concern about them. These findings from Malaysia were just confirming what most patients expected from nurses in this study. Another study which was done in Iran by Kalyani, Kashkooli, Molazem, and Jamshidi (2014), also found that all the participants considered having good behavior as a priority for nursing and patient care. But, most of the studies done on patient expectations have not explicitly found how gender influences patients' expectations regarding nursing care. Likewise the findings of this study did not show that there were statistically significant differences in responses by gender distribution. Hence gender had little influence on patients' expectations.

Participants' mean responses by religion, agreed that they were expecting nurses to be kind, cheerful, and responsive but not rude. The study also revealed that there were more Christians than Muslims that participated in the study. The Christians and Muslims agreed that they expected nurses to be kind. Although, the study revealed that Muslims had a higher mean response than Christians, there were no significant differences in responses 
by religion distribution. Unfortunately, the literature has shown that no study has been done on how religion would influence patients' expectations regarding nursing care. But according to this study findings, religion did not influence what patients were expecting from nursing care.

Participants mean responses on patients' expectations by marital status revealed that all were expecting that nurses should be kind, cheerful, and responsive and strongly disagreed that nurses should be rude. The separated and widowed strongly agreed that they were expecting nurses to be cheerful and also to be responsive to patients' concerns. The study also showed that there were statistically significant differences among mean patients' responses by marital status on patients' expectation of nurses' responsiveness to patient's concerns $(\mathrm{F}=4.018, \mathrm{p}=0.004)$. It could be said that marital status had some influences on what patients were expecting from nurses.

The study revealed that patients were expecting nurses to be knowledgeable and competent of their work. That is why patients become dissatisfied with nursing care if inadequate information about their condition and treatment was given. Similar study was done in India which found that there was relatively higher percentage of patients $(31.6 \%)$ who had poor perceptions regarding explanation and information (Samina, et al, 2008). The findings conquer with Farooq and Rasool, (2014), because they found 70\% of patients were satisfied with explanation regarding their diseases in tertiary hospitals in Pakistan. Therefore, it is expected of nurses to be knowledgeable for them to be able in explaining patient's condition and treatment options to their patients. The study also revealed that participants were expecting that nurses should be respectful when attending to the patients. Provision of privacy and keeping patients' confidentiality is one way of showing respect for patients. These findings are in consistent with a study done in Pakistan whereby $94 \%$ of participants liked nursing practice of keeping privacy of patients (Khan, Hassan, Anwar, Babar, and Babar, 2007). Participants were in agreement with almost all expectations except that they did not agree that they expected nurses to be rude and harsh. These findings are in consistent with the study done in Turkey on patients' expectations of nursing care. It was found that patients were expecting nurses to be cheerful, knowledgeable and competent, and to be informed of the treatment (Ozsoy, et al, 2007). It was also observed that patients whose expectations were met, were very satisfied with nursing care. Therefore, this study had revealed that patients were expecting that nurses should be knowledgeable of their work, respectful, providing explanations, kind, and cheerful. 


\section{Limitations}

The study did not establish qualitative information on patient's experiences and expectations because of the nature of its design since it used a structured data collection tool.

\section{Conclusion}

The study found that patients' expectations can have some influences on patients' satisfaction level of care. When patients' expectations are not met, their level of satisfaction also declined. Patients felt satisfied as nurses met most of their expectations. Therefore, it was about how much of patients' expectations nurses managed to meet in order to get patients' satisfaction. Therefore, patients need to be given adequate correct information about their condition, treatment and procedures in the ward. Patient assessment should include patients' care expectations especially at admission so as to incorporate them in the nursing care plan. It could be concluded that regardless of patients' various characteristics, nurses should show kindness, cheerfulness, responsiveness, knowledgeable and honest when proving nursing care. Good nurse-patient relationship is vital in promoting trust between nurse and patient, and hence chances of patients labeling nurses as rude people would be minimized. The results can be generalized in Kenya because $\mathrm{KNH}$ receives patients from all parts of the country as a referral hospital.

\section{References:}

1. Aldaqal S.M., Alghamdi H., Alturk H., El-deek B.S., \& Kensarah A.A. (2012). Determinants of Patients Satisfaction in Surgical Ward at a University Hospital in Saudi Arabia, Life Science Journal, Vol. 9, No. 1 pp 277-280

2. Burhans L.M. \& Alligood M.R. (2010). Quality Nursing care in the Words of Nurses: Journal of Advanced Nursing, Vol.66. Issue 8 (pp1689-1697).

3. Buttell P, Hendler R, \& Daley J, (2007) Quality in Healthcare: Concepts and Practice. The Business of Healthcare. Vol.3. Issue 003 (pp 61-95)

4. Farooq U. \& Rasool A. (2014), Assessment of Patients' Satisfaction in Medical and Surgical Wards in a Tertiary care Hospital. Journal of Ayub Medical College, Abbottabad. (p147-150)

5. Ghana Health Services (2004). Health Care Quality Assurance Manual: http://www.ghanaqhp.org/fileadmin visited on 6/12/2011

6. Health Resources and Services Administration, \{HRSA\} (2011), U.S. department of Health and Human Services. https://www.hrsa.gov/quality/ 
7. Kalyan M.N., Kashkooli R.I., Molazem Z., \& Jamshidi N (2014). Qualitative inquiry into Patient's Expectations regarding Nurses and Nursing care, Advances in Nursing. Hindawi Publications Corporation.

8. Khan M.H., Hassan R., Anwar S., Babar T.S., \& Babar K.S. (2007). Patient Satisfaction with Nursing care. Rawal Medical Journal: Vol.32, Issue 1 pp 27-29.

9. Moscato S.R., Valanis B., Gullion C.M., Tanner C., Shepiro S.E., \& Izumi S. (2007).

10. Predictors of Patients Satisfaction with Telephone nursing services: Clinical Nursing Research. Vol.16. Issue 2. http://www.hinarigw.who.int.

11. Muhondwa E.P.Y., Leshabari M.T., Mwangu M., Mbembali N., \& Ezekiel M.J. (2008).

12. Patients Satisfaction at Muhimbili National Hospital in DaresSalaam, Tanzania: East African Journal of Public Health. Vol. 5 Issue 2

13. Nankumbi J. (2005). Patients' Attitude Towards Satisfaction with the Quality of Nursing Care. Makerere University Research Reporting. http://www.dspace.mak.au.ug. Visited on 28/11/2011

14. National Nursing Research Unit (2008). High Quality nursing careWhat is it and How can we best ensure its delivery. Policy Plus Evidence, Issues and Opinions in Health care: Issue: 13.

15. Ojwang B.O, Ogutu E.A \& Matu P.M. (2010). Nurses' Impoliteness as an Impediment to Patients Rights in selected Kenyan Hospitals. http://www.hhrjournal.org/index.php/hhr/article/viewarticle/372/577 visited on 28/11/2011

16. Ozsoy S.A, Ozgur G. \& Akyol A.D. (2007). Patients Expectation and Satisfaction with Nursing care in Turkey: a literature Review. International Nursing Review. Vol. 54 pp249-255

17. Rafii F, Hajinezhad M.E. \& Haghani H. (2008). Nurse caring in Iran and its relationship with Patient satisfaction: Australian Journal of Advanced Nursing. Vol. 26. Issue2 pp 75-84

18. Reck D.L. (2013) Can and Should Nurses Be Aware of Patients' Expectations for Their Nursing Care? Nursing administration quarterly/April-June 2013. Lippincott Williams \& Wilkins.

19. Redsell S., Jackson C., Stokes T., Hastings A., \& Baker R. (2007). Patients' Expectations of first contact care Consultations with Nurse and General Practitioner in Primary care. The University of Nottingham, United Kingdom. http://eprints.nottingham.ac.uk/1320/1/patient_expectations.p df 
20. Samina M, Gadri G.J, Tabish S.A, Samiya M \& Riyaz R. (2008). Patients' Perception of nursing care at Large Teaching Hospital in India: International Journal of Health Sciences. Vol.2. Issue. 2 pp92100

21. Shirley T.K.Y. \& Norazliah S. (2012). Surgical Patients' Satisfaction of Nursing Care at the Orthopedic Wards in Hospital University Sains Malaysia (HUSM), Health and the Environment Journal, Vol. 3, No.1 pp 36-43

22. World Health Organization (2006), Quality of care: A process for making strategic choices in health system. http://www.who.int/management/quality/assurance/qualitycare_B.def .pdf. visited on 10/12/2011

23. Zhao S.H. \& Akkadechanunt T. (2011). Patients' Perceptions of Quality Nursing Care in a Chinese Hospital: International Journal of Nursing and Midwifery. Vol. 3 Issue 9. Pp145-149. 